\section{Commentary: Transcarotid versus direct aortic transthoracic aortic valve replacement: How best to enter the room where it happens?}

\author{
Moritz C. Wyler von Ballmoos, MD, and \\ Michael J. Reardon, MD
}

Transcatheter aortic valve replacement (TAVR) has fundamentally changed our treatment approach to severe aortic stenosis. Built on a series of randomized, prospective clinical trials, TAVR is now approved for patients at all risk levels. ${ }^{1-7}$ Procedural risk of mortality was at the center of those trials as we moved from high, to intermediate, and to low risk for both surgical aortic valve replacement and TAVR. The early survival benefit of TAVR compared with the surgical option was particularly pronounced as we moved down the risk scale. This is likely due to improved TAVR devices, sophisticated imaging, and refined implantation techniques. One area of notable improvement for TAVR has been the access used to deliver the valve. For example, in the Placement of Aortic Transcatheter Valve Trial IA high-risk trial, almost $30 \%$ of TAVR cases were done with a trans-apical access (TA), with the rest being trans-femoral (TF) or so-called alternative access consisting of anything but TA and $\mathrm{TF}^{2}$ In the CoreValve Extreme Risk trial, alternative access consisted of either transaxillary or direct aortic (DA) access in $11 \%$ and $12 \%$ of cases, respectively. ${ }^{8}$ With continuing refinement of technique and smaller delivery systems, the use of alternative access has gradually decreased. In the Evolut Low Risk Randomized Trial, access was TF in $98 \%$ of cases, trans-axillary in $1.4 \%$, and DA in a mere $0.6 \%$.

However, trials enroll extremely manicured cohorts, and in daily clinical practice patients with a wider spectrum of

From the Department of Cardiovascular Surgery, Houston Methodist Hospital, Houston, Tex.

Disclosures: The authors reported no conflicts of interest.

The Journal policy requires editors and reviewers to disclose conflicts of interest and to decline handling or reviewing manuscripts for which they may have a conflict of interest. The editors and reviewers of this article have no conflicts of interest.

Received for publication Sept 30, 2020; revisions received Sept 30, 2020; accepted for publication Oct 1, 2020; available ahead of print Oct 21, 2020.

Address for reprints: Michael J. Reardon, MD, Department of Cardiovascular Surgery, Houston Methodist Hospital, 6565 Fannin St, Houston, TX 77030 (E-mail: mreardon@houstonmethodist.org).

J Thorac Cardiovasc Surg 2022;164:516-7

$0022-5223 / \$ 36.00$

Copyright (C) 2020 by The American Association for Thoracic Surgery

https://doi.org/10.1016/j.jtcvs.2020.10.007

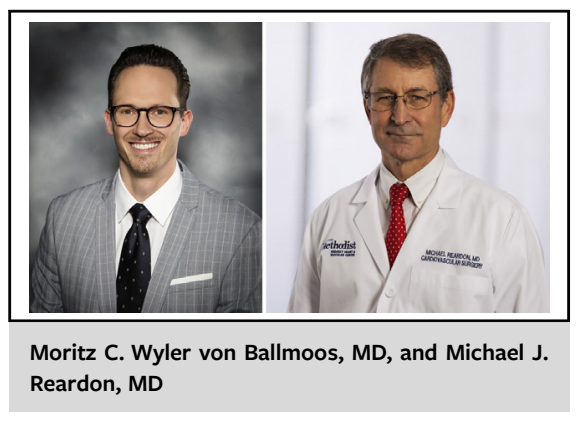

CENTRAL MESSAGE

TAVR procedures with access that does not penetrate the chest wall are preferable to those that do.

vascular disease and comorbidities are being treated. This has prompted creativity among TAVR surgeons to explore other access options, including trans-carotid (TC) access. The TC access approach to TAVR has been pioneered in the United States by Allen and colleagues. ${ }^{9}$ Allen and colleagues ${ }^{9}$ compare the outcomes with a TC approach to TAVR with trans-thoracic wall access, including TA and DA, which were considered a single group. They do this by analysis of the Society of Thoracic Surgeons/American College of Cardiology Transcatheter Valve Therapy Registry database between June 2015 and July 2019 looking only at the current generation of the Sapien S3 valve (Edwards Lifesciences, Irvine, Calif). During this time frame, there were 121,069 TAVR cases done with the Sapien S3 valve. Of these, $5.8 \%(6975$ out of 121,069$)$ were done by a non-TF route. Further, 10\% (699 out of 6975) of the non-TF cases were done using the TC approach and $41 \%$ (2880 out of 6975) were done by a trans-thoracic wall (DA or TA) approach. They found that TC TAVR at 30 days was associated with less mortality, less new-onset atrial fibrillation, fewer readmissions, shorter length of stay, shorter intensive care unit time, and greater improvement in Kansas City Cardiomyopathy Questionnaire score. There was no difference in stroke or major vascular complications. Further, they used a propensity-matched cohort of 667 TC TAVR patients with 1334 trans-thoracic wall TAVR patients (608 TA and 726 DA) and found similar results. From this, it appears that TC TAVR should be preferred to a trans-thoracic wall approach when possible. This does not tell us which nontrans-thoracic wall access is best.

These findings are certainly suggestive of the safety when using TC access; however, its association with outcomes 
such as mortality, stroke, and length of stay need to be interpreted with caution. Whereas propensity score matching is now often used to make treatment groups more comparable, one must remember the conditions that are required to obtain valid estimates. Among the most basic requirements is that of a nonzero probability in either group. For example, a significant proportion of patients selected for DA access will have no suitable peripheral vessels for access, likely because of more severe peripheral vascular disease or other conditions such as dialysis access or a patent left internal thoracic artery graft, and therefore have no probability of being in the TF, TA, or TC group. Propensity score matching cannot overcome that, and will not yield valid estimates in those scenarios. Only randomization could convincingly overcome that issue.

Further, the reader should note that Allen and colleagues' Figure $1^{9}$ displays the decrease of transthoracic and increase in TC TAVRs only, without considering TF access-the most prevalent access-and therefore can be misleading.

Early experience in the Placement of Aortic Transcatheter Valve Trials showed the TF approach to be preferable to the TA approach. ${ }^{2}$ In the Self-Expanding CoreValve trials, TF was found to be preferable to DA access. ${ }^{10}$ Not surprisingly, patients recover slower if you use an access that violates the chest wall and prefer approaches that do not violate the chest wall. For most TAVR implanters, nontrans-thoracic access is chosen whenever possible. What remains unknown is which non-trans-thoracic access is best? The most common approach is TF. The next developed was the subclavian or trans-axillary approach, which has been shown to yield equivalent results to TF. TC and transcaval both also allow access without transgression of the chest wall. In fact, we have shown that a DA approach can be obtained using a suprasternal incision without crossing the thoracic cage. ${ }^{11}$ In our opinion, all of these approaches are likely to yield similar results and faster recovery than TA access or DA access, even in the absence of confounders. We salute the authors for their leadership in developing the TC approach to TAVR and providing us with the current comparison. This highlights the need to redefine how we classify the access the TAVR takes because there are now a number of approaches that yield results that should qualify them to be appropriate primary modes of access. To get to the valve, we can break through the barrier of the chest wall or go through a door that opens easily. TC and the other non-trans-thoracic approaches provide this door-let's use it.

\section{References}

1. Leon MB, Smith CR, Mack M, Miller DC, Moses JW, Svensson LG, et al. Transcatheter aortic-valve implantation for aortic stenosis in patients who cannot undergo surgery. N Engl J Med. 2010;363:1597-607.

2. Smith CR, Leon MB, Mack MJ, Miller DC, Moses JW, Svensson LG, et al. Transcatheter versus surgical aortic-valve replacement in high-risk patients. $N$ Engl J Med. 2011;364:2187-98.

3. Adams DH, Popma JJ, Reardon MJ, Yakubov SJ, Coselli JS, Deeb GM, et al. Transcatheter aortic-valve replacement with a self-expanding prosthesis. $N$ Engl J Med. 2014;370:1790-8.

4. Leon MB, Smith CR, Mack MJ, Makkar RR, Svensson LG, Kodali SK, et al. Transcatheter or surgical aortic-valve replacement in intermediate-risk patients. N Engl J Med. 2016;374:1609-20.

5. Reardon MJ, Van Mieghem NM, Popma JJ, Kleiman NS, Søndergaard L, Mumtaz M, et al. Surgical or transcatheter aortic-valve replacement in intermediate-risk patients. N Engl J Med. 2017;376:1321-31.

6. Mack MJ, Leon MB, Thourani VH, Makkar R, Kodali SK, Russo M, et al. Transcatheter aortic-valve replacement with a balloon-expandable valve in low-risk patients. N Engl J Med. 2019;380:1695-705.

7. Popma JJ, Deeb GM, Yakubov SJ, Mumtaz M, Gada H, O’Hair D, et al. Transcatheter aortic-valve replacement with a self-expanding valve in low-risk patients. N Engl J Med. 2019;380:1706-15.

8. Popma JJ, Adams DH, Reardon MJ, Yakubov SJ, Kleiman NS, Heimansohn D, et al. Transcatheter aortic valve replacement using a self-expanding bioprosthesis in patients with severe aortic stenosis at extreme risk for surgery. J Am Coll Cardiol. 2014;63:1972-81.

9. Allen KB, Saxon J, Hermiller J, Heimansohn D, McKay RG, Cheema M, et al. Transcarotid versus transthoracic access for transcatheter aortic valve replacement: a propensity matched analysis. J Thorac Cardiovasc Surg. 2022; 164:506-15.

10. Reardon MJ, Adams DH, Coselli JS, Deeb GM, Kleiman NS, Chetcuti S, et al. Self-expanding transcatheter aortic valve replacement using alternative access sites in symptomatic patients with severe aortic stenosis deemed extreme risk of surgery. J Thorac Cardiovasc Surg. 2014;148:2869-76.e1-7.

11. Kiser AC, O’Neill WW, de Marchena E, Stack R, Zarate M, Dager A, et al Suprasternal direct aortic approach transcatheter aortic valve replacement avoids sternotomy and thoracotomy: first-in-man experience. Eur J Cardiothorac Surg. 2015;48:778-83 